Supplement of Clim. Past, 14, 825-856, 2018

https://doi.org/10.5194/cp-14-825-2018-supplement

(c) Author(s) 2018. This work is distributed under

the Creative Commons Attribution 4.0 License.

(c) (1)

Supplement of

\title{
On the mechanisms of warming the mid-Pliocene and the inference of a hierarchy of climate sensitivities with relevance to the understanding of climate futures
}

Deepak Chandan and W. Richard Peltier

Correspondence to: Deepak Chandan (dchandan@atmosp.physics.utoronto.ca)

The copyright of individual parts of the supplement might differ from the CC BY 4.0 License. 
Table 1: Ocean temperature trends globally and for the different oceanic depths: upper ocean $(0-550 \mathrm{~m})$, middle ocean $(550-1850 \mathrm{~m})$ and lower ocean (below $1850 \mathrm{~m})$. All values are in units of ${ }^{\circ} \mathrm{C}$ century ${ }^{-1}$.

\begin{tabular}{llllll}
\hline Expt. & $\begin{array}{l}\text { Global } \\
\text { Ocean }\end{array}$ & SST & $\begin{array}{l}\text { Upper } \\
\text { Ocean }\end{array}$ & $\begin{array}{l}\text { Middle } \\
\text { Ocean }\end{array}$ & $\begin{array}{l}\text { Lower } \\
\text { Ocean }\end{array}$ \\
\hline $\mathrm{E}^{280 \dagger}$ & 0.03 & 0.01 & 0.01 & 0.02 & 0.05 \\
$\mathrm{E}^{400 \dagger}$ & 0.06 & 0.01 & 0.03 & 0.05 & 0.07 \\
$\mathrm{E} o i^{280}$ & 0.05 & 0.02 & 0.03 & 0.05 & 0.05 \\
$\mathrm{E} o i^{400 \dagger}$ & 0.05 & 0.02 & 0.04 & 0.05 & 0.05 \\
$\mathrm{E} o i^{450 \dagger}$ & 0.05 & 0.04 & 0.03 & 0.05 & 0.06 \\
$\mathrm{E} o^{280}$ & 0.02 & -0.01 & 0.00 & 0.01 & 0.03 \\
$\mathrm{E} o^{400}$ & 0.05 & 0.03 & 0.03 & 0.05 & 0.06 \\
$\mathrm{E} i^{280}$ & 0.04 & 0.02 & 0.02 & 0.04 & 0.05 \\
$\mathrm{E} i^{400}$ & 0.05 & 0.00 & 0.01 & 0.06 & 0.06 \\
\hline
\end{tabular}

$\dagger$. From Chandan and Peltier (2017).

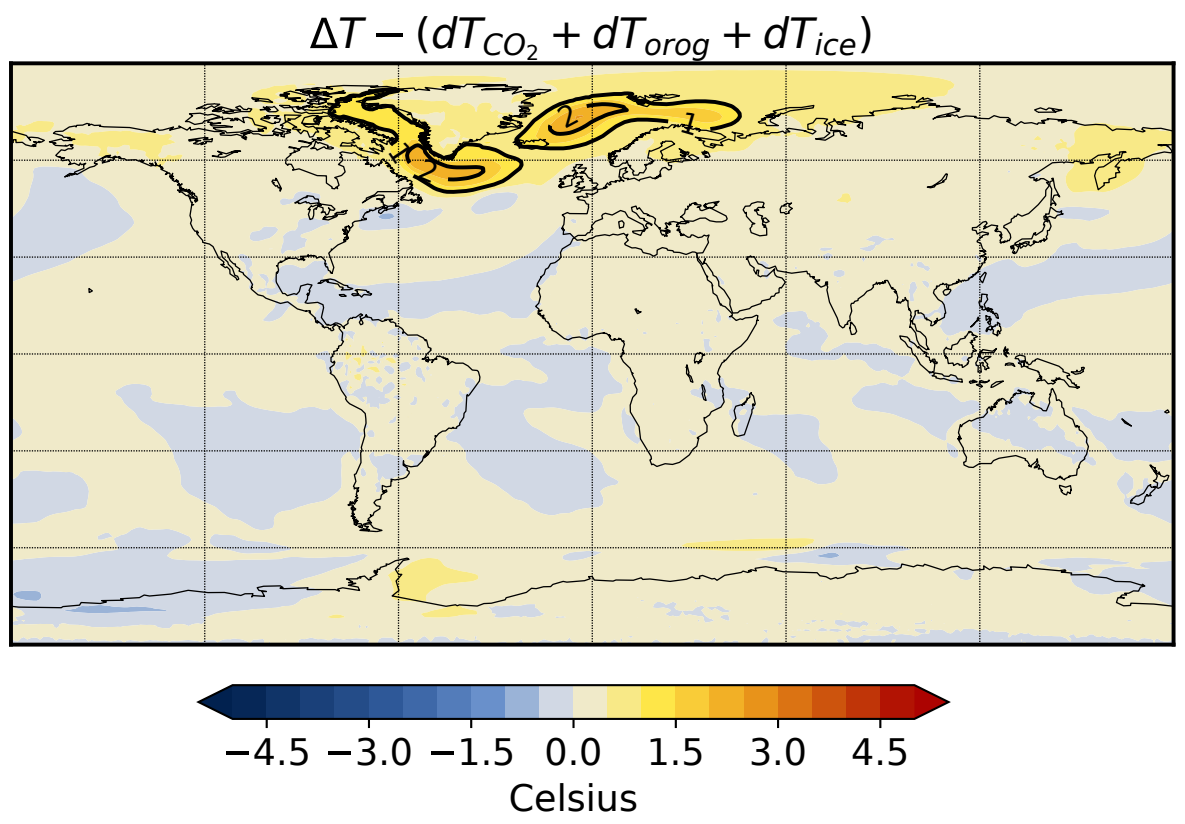

Figure S1: The residual $\Delta T-\left(d T_{C O_{2}}+d T_{\text {orog }}+d T_{i c e}\right)$ for the factorization of the MASAT given in the paper. 

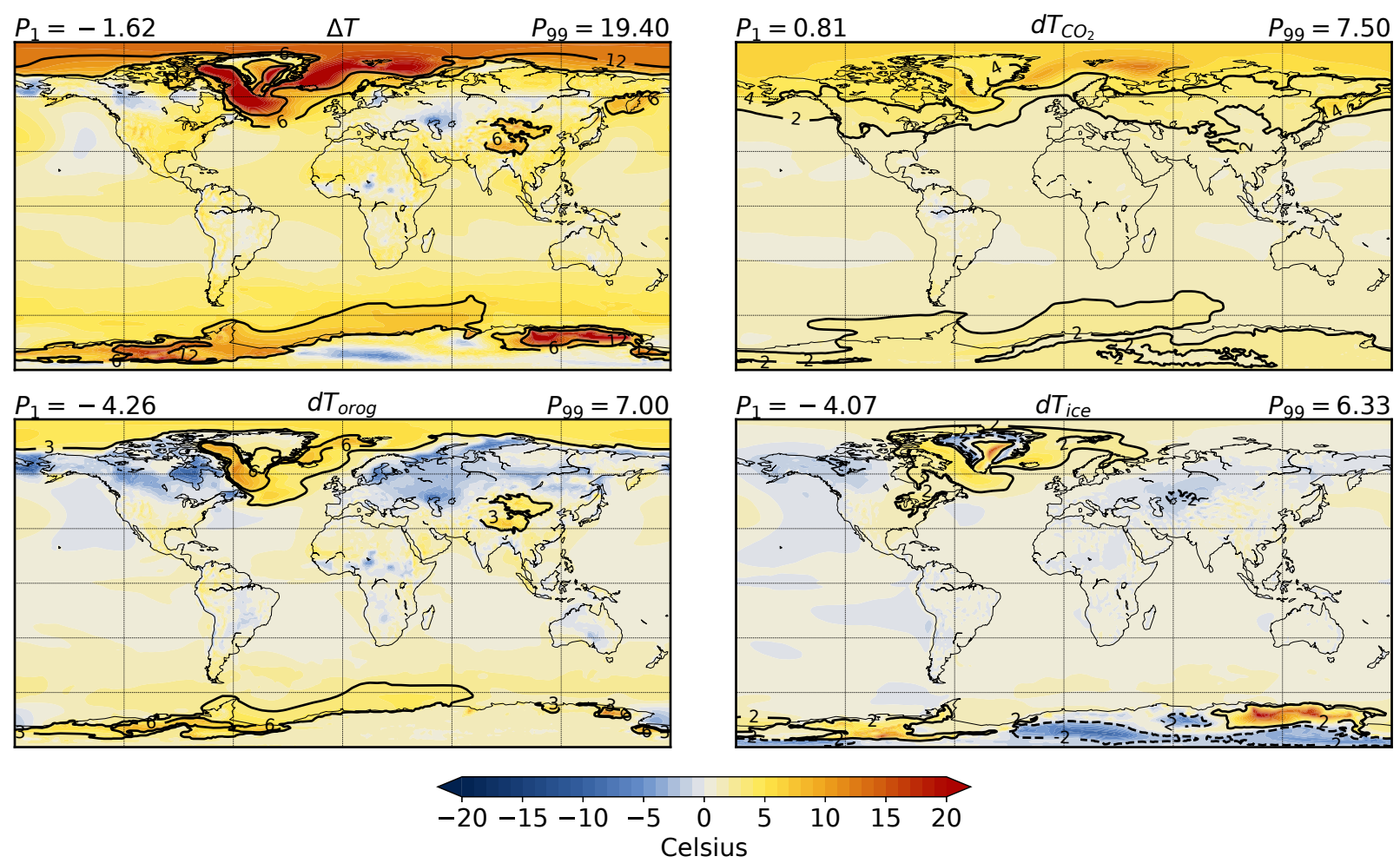

Figure S2: DJF $2 \mathrm{~m}$ SAT anomaly between the mid-Pliocene and the PI $(\Delta T)$ and its factorization into contributions from change in atmospheric $p \mathrm{CO}_{2}\left(d T_{\mathrm{CO}_{2}}\right)$, change in orography $\left(d T_{\text {orog }}\right)$ and change in ice sheet $\left(d T_{i c e}\right)$. The $1^{\text {st }}$ and the $99^{\text {th }}$ percentiles of the quantities plotted are shown above each sub-figure.

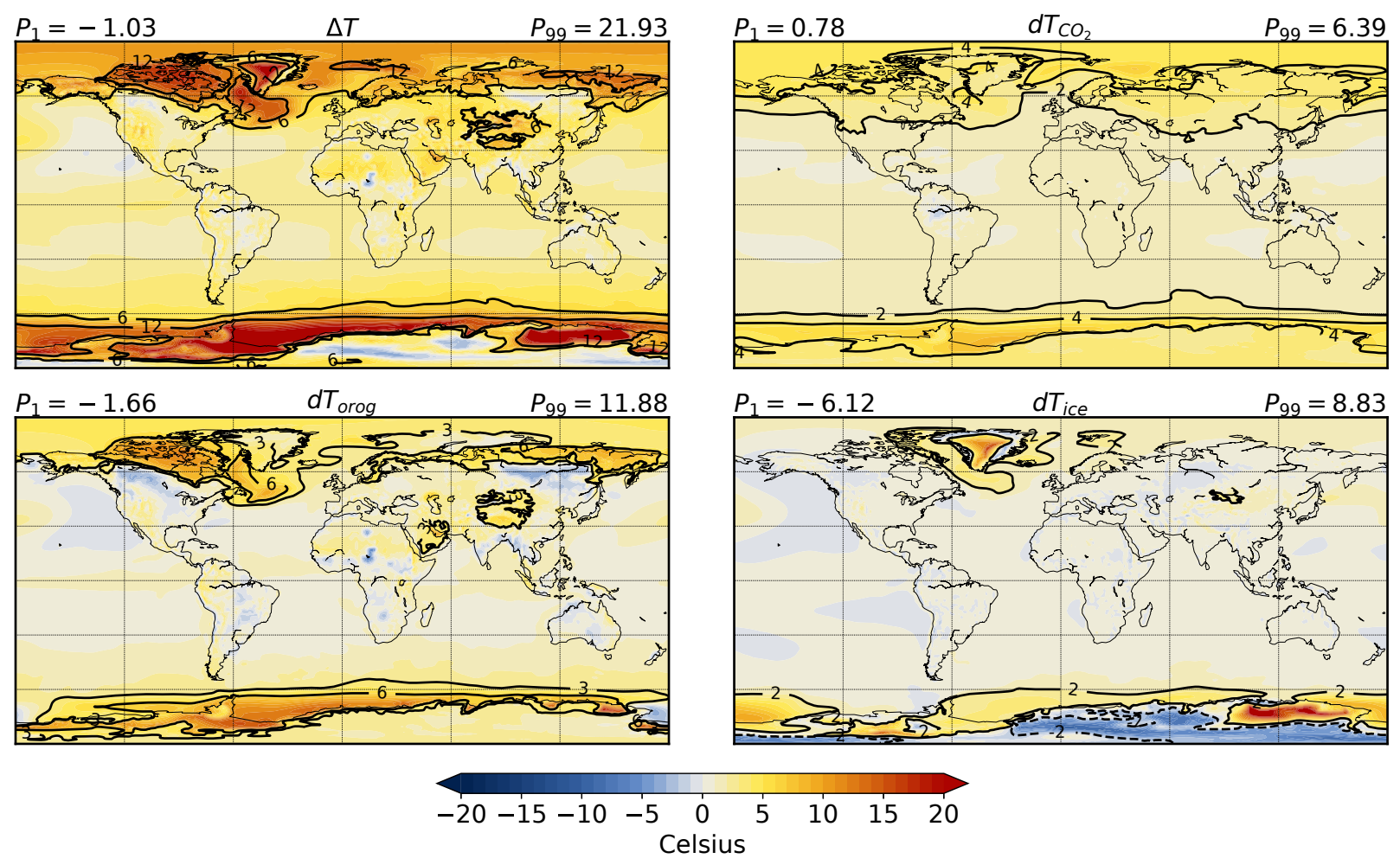

Figure S3: Similar to Figure S2 but for the season MAM. 

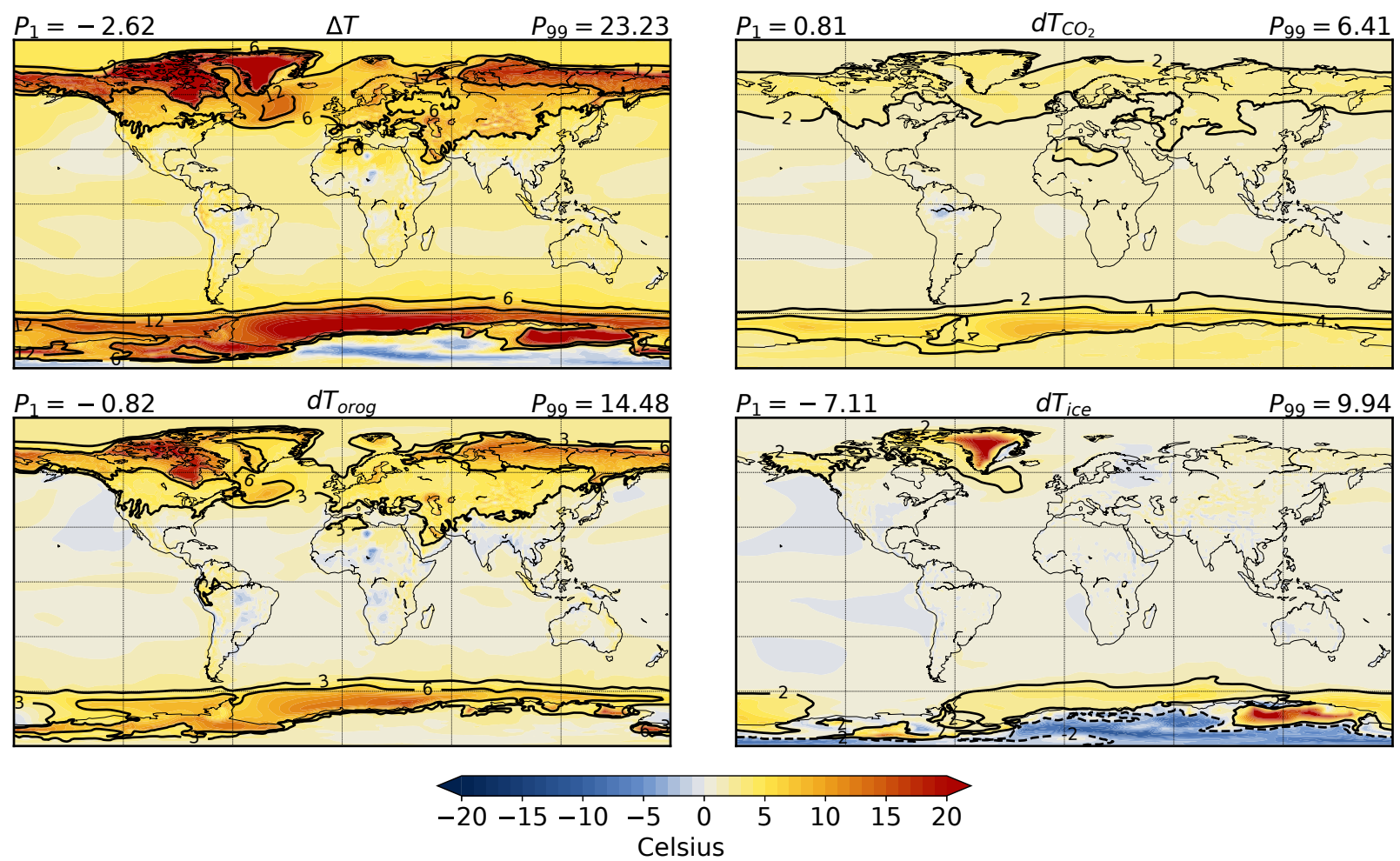

Figure S4: Similar to Figure S2 but for the season JJA.
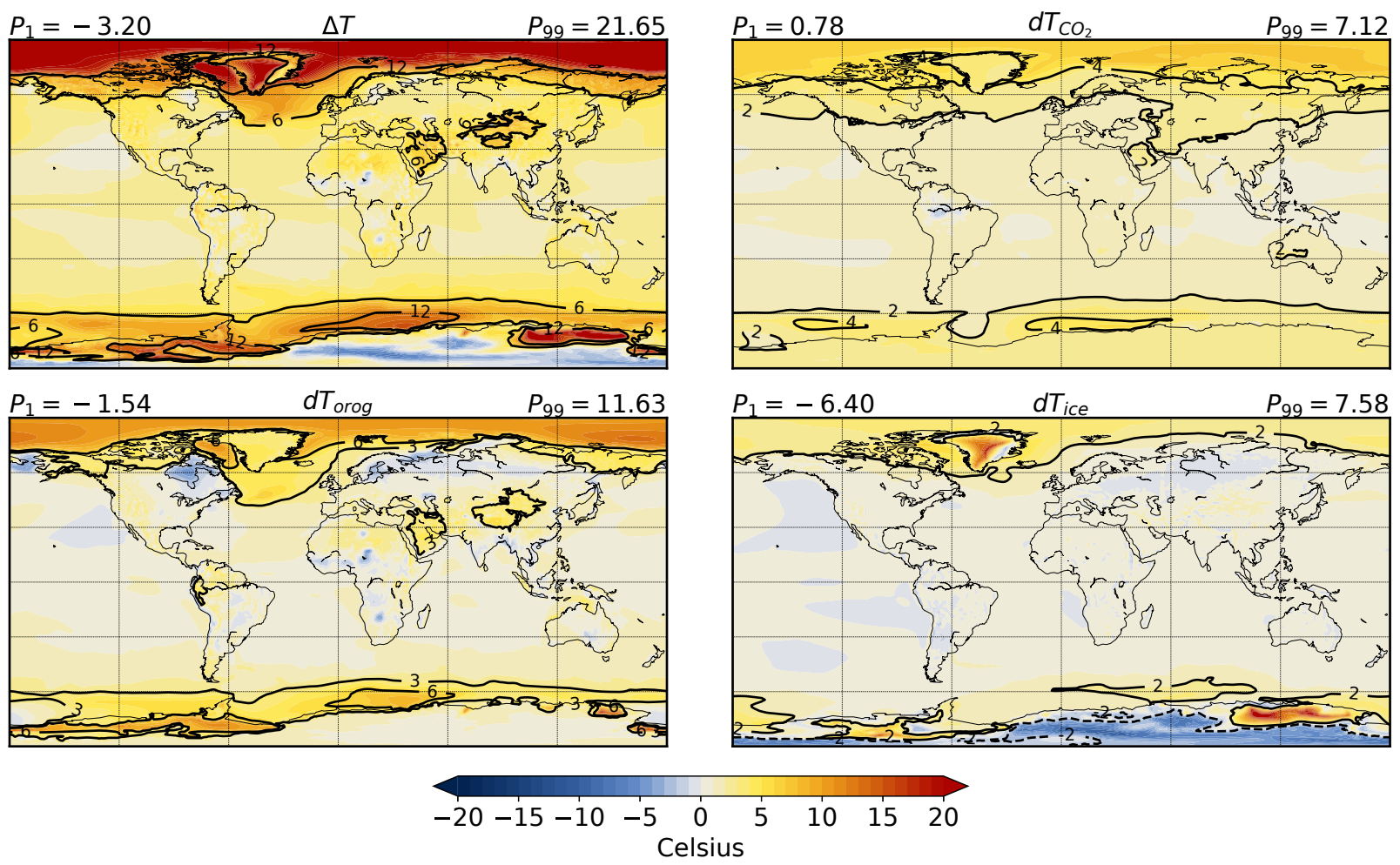

Figure S5: Similar to Figure S2 but for the season SON. 


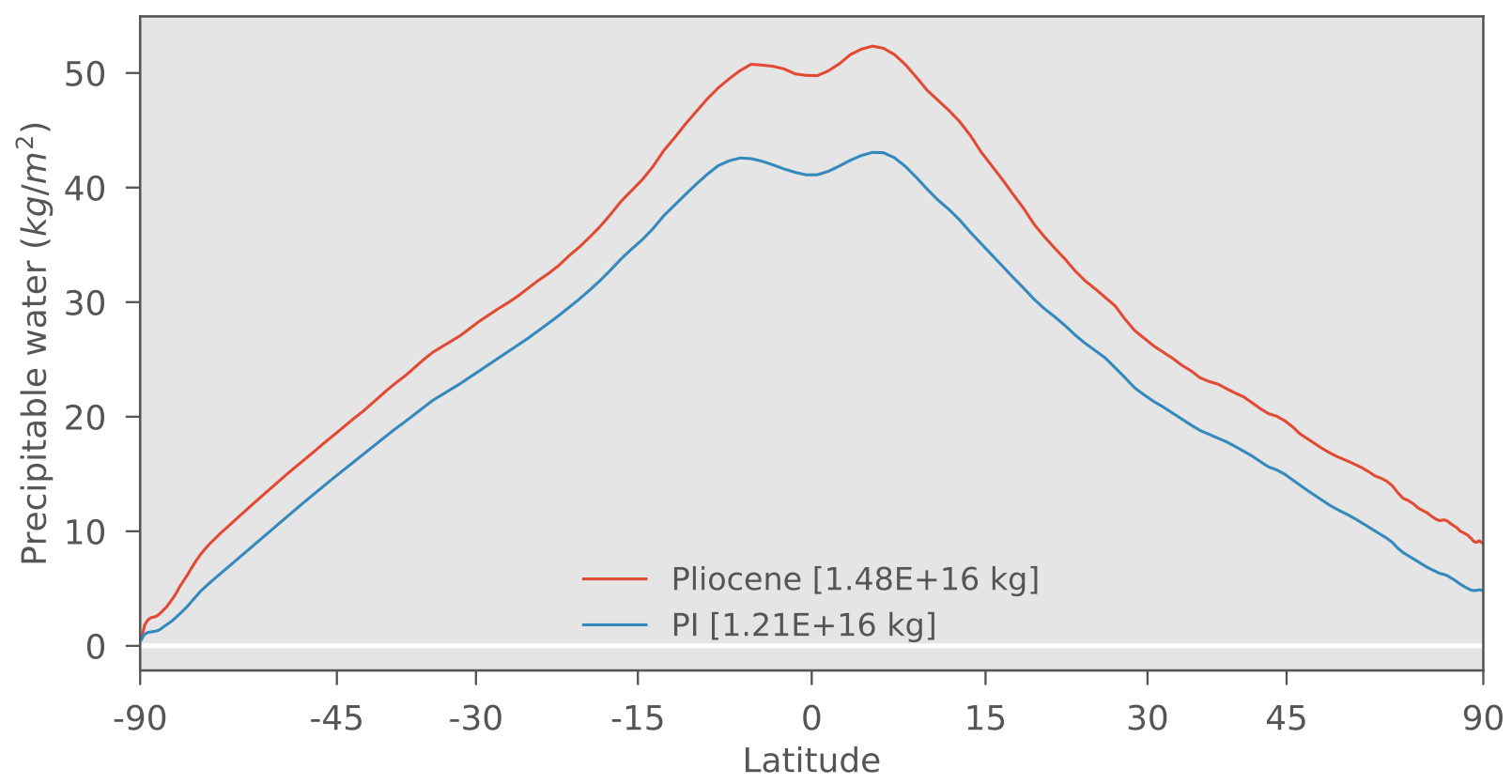

Figure S6: Zonal means of the total precipitable water in the atmospheres of the PI and the midPliocene. The number accompanying the legend indicates the globally integrated water content. 

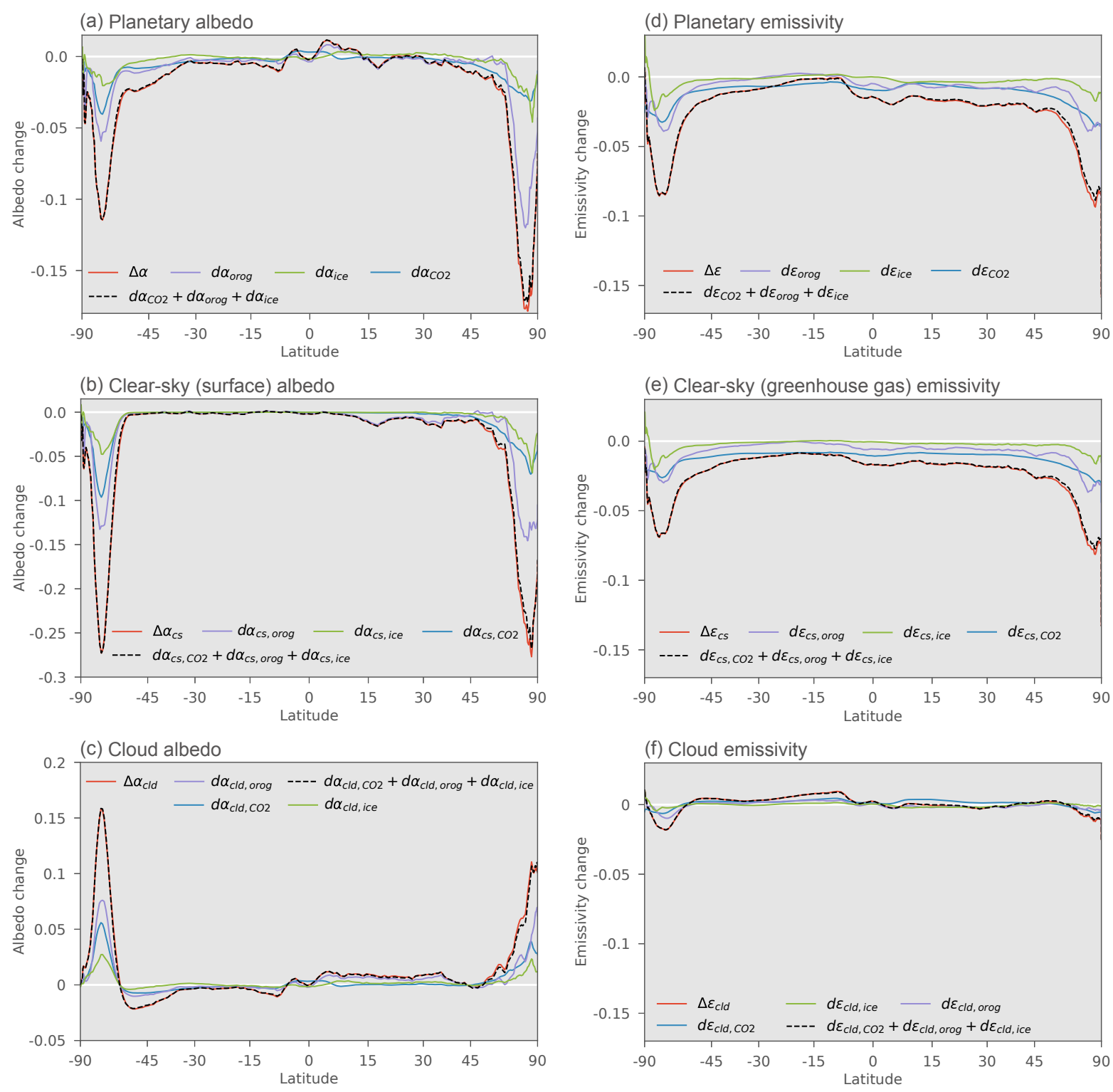

Figure S7: Factorization of the PI to Pliocene change in zonal mean (a) planetary albedo, (b) clear-sky or surface albedo, (c) cloud albedo, (d) planetary emissivity, (e) clear-sky emissivity, or emissivity change due to change in greenhouse gas concentrations including water vapor, and (f) cloud emissivity, into contributions arising from changes made to the following boundary conditions: orography (purple), ice-sheet (green) and atmospheric $\mathrm{CO}_{2}$ concentration (blue). In each figure, the red curve is the total PI to Pliocene change in the property plotted on the figure and the dashed black line is the sum of the factorized components and which is seen to track the total change very closely. 

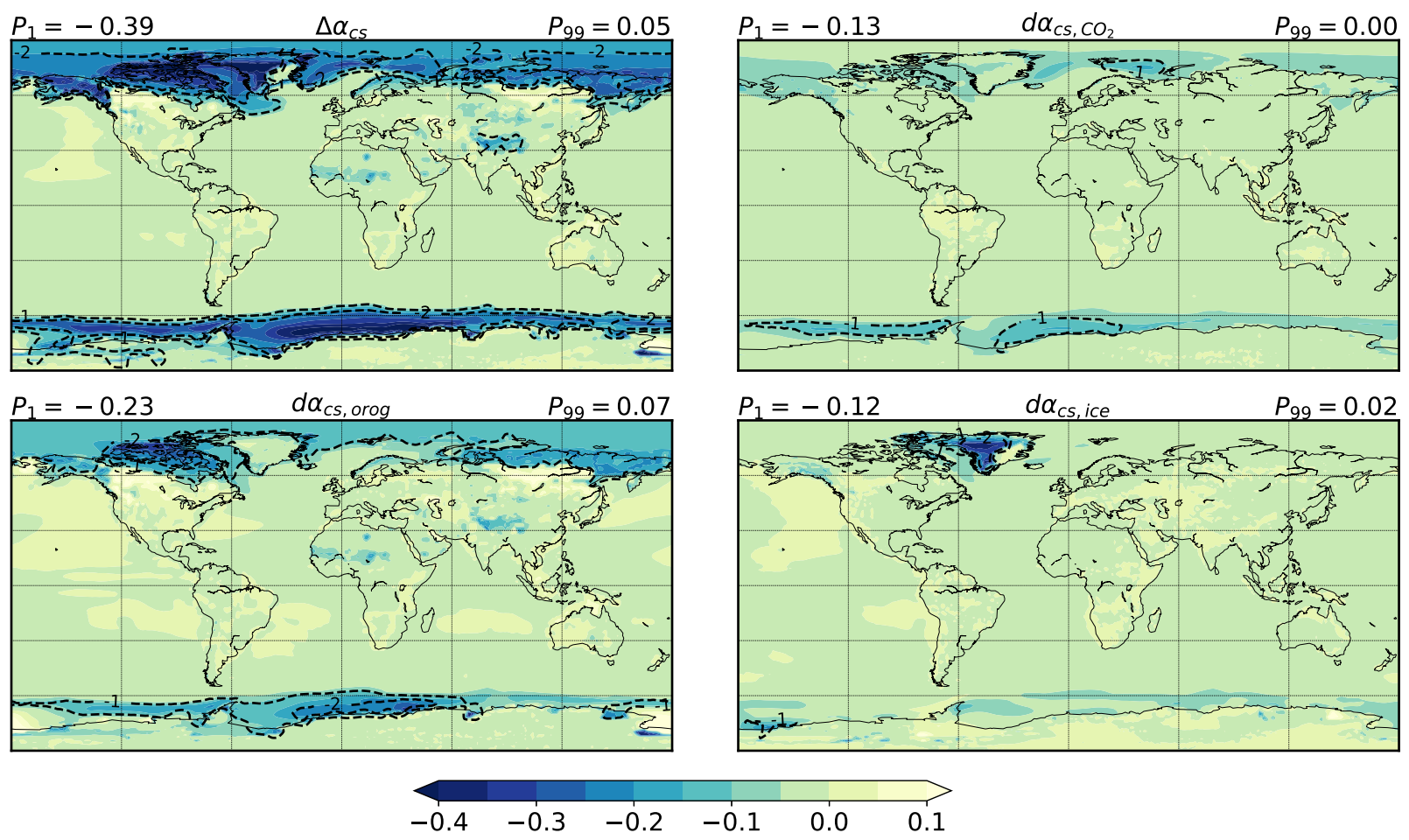

Figure S8: The total clear-sky albedo change and its factorization into contributions from changes to $p \mathrm{CO}_{2}$, orography and ice sheets. 

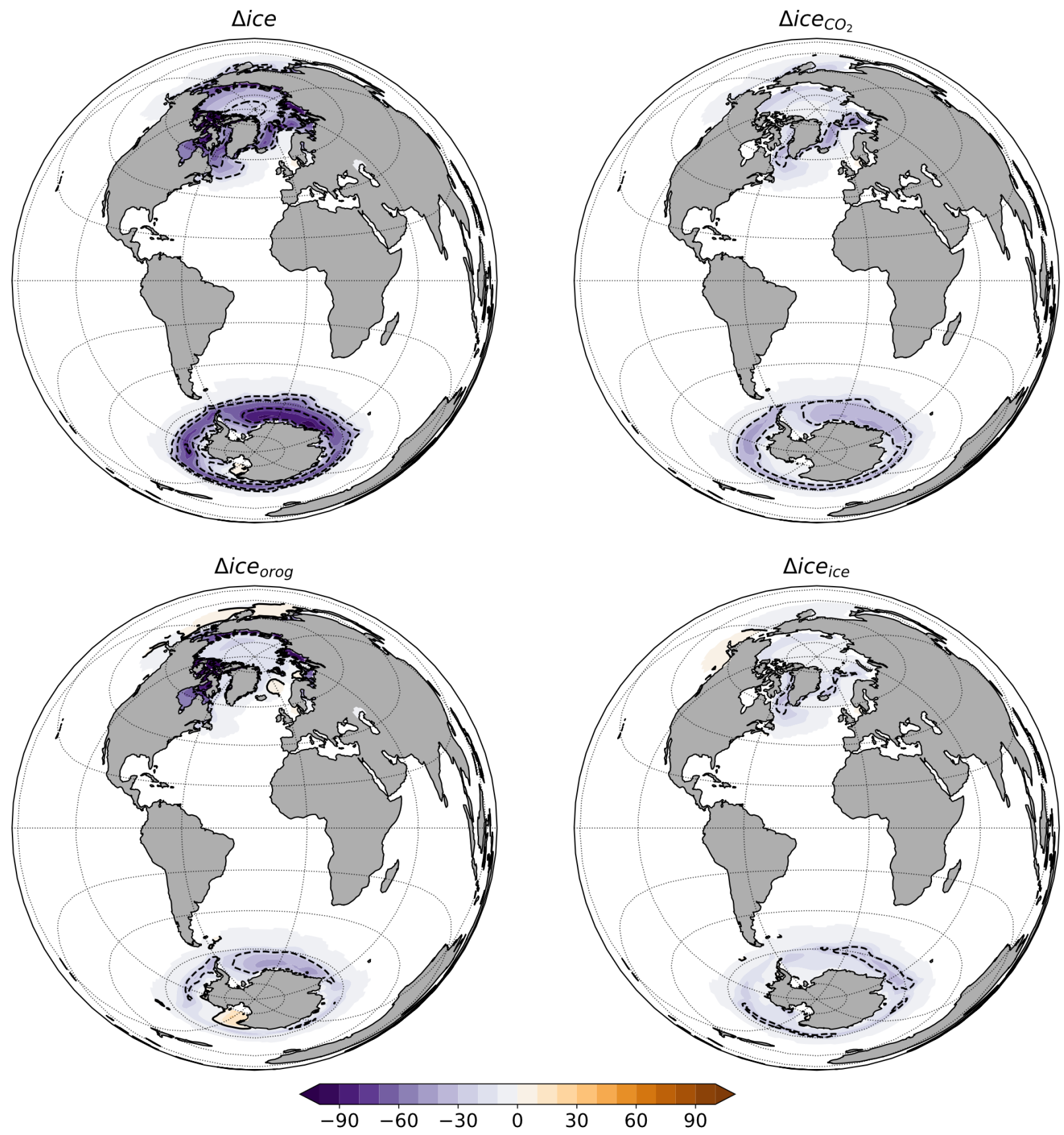

Figure S9: Annual sea ice concentration anomaly between the mid-Pliocene and the PI ( $\Delta$ ice) and its factorization into contributions from change in atmospheric $p \mathrm{CO}_{2}\left(\Delta i c e_{\mathrm{CO}_{2}}\right)$, change in orography $\left(\Delta i_{i c e_{\text {orog }}}\right)$ and change in ice sheet $\left(\Delta i c e_{i c e}\right)$. 


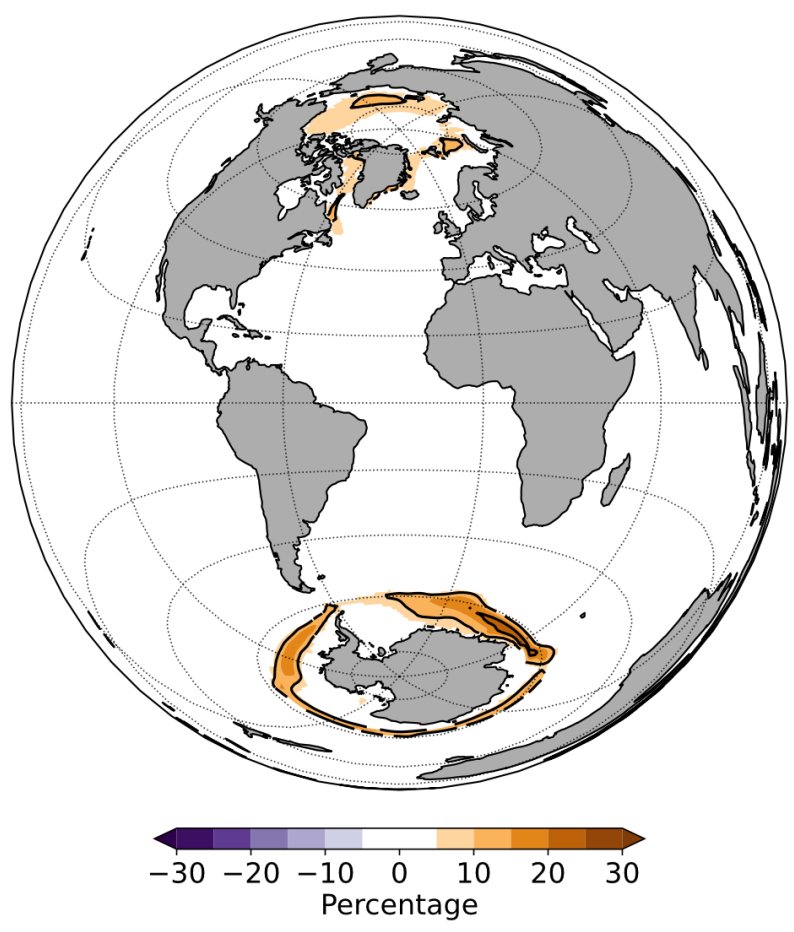

Figure S10: The residual from the factorization of sea ice anomaly shown in Fig. S9. 


\section{References}

Chandan, D. and Peltier, W. R.: Regional and global climate for the mid-Pliocene using the University of Toronto version of CCSM4 and PlioMIP2 boundary conditions, Climate of the Past, 13, 919-942, doi:10.5194/cp-13-919-2017, 2017. 